\title{
Turismo e ilheidade: o olhar de crianças residentes da vila de encantadas, na Ilha do Mel (Paranaguá - PR)
}

\author{
Tourism and islander culture: the look of resident children of the village of encantadas, in \\ the Ilha do Mel (Paranaguá - PR)
}

Turismo e cultura isleña: el mirada de los ñinos que viven en el pueblo de encantadas, em Ilha do Mel (Paranaguá - PR)

\section{Letícia Gomes de Oliveira ${ }^{1}$ Elizabete Sayuri Kushano ${ }^{2}$}

Resumo: Este estudo buscou o olhar de crianças ilhéus sobre as práticas turísticas na região onde vivem, contribuindo para a reflexão sobre a humanização do turismo, conhecendo o cotidiano, a cultura e os sentimentos de ilheidade a partir da perspectiva de crianças residentes, desvelando como elas se relacionam com o turismo em seu lugarterritório. A abordagem utilizada foi etnográfica, realizada a partir de observações in loco, de questionários e entrevistas aplicados a estudantes do 5ํao de uma escola pública da Vila de Encantadas, na Ilha do Mel e de entrevista com a professora responsável pela referida turma. Os resultados apontaram que as crianças pesquisadas tinham sensível conhecimento sobre o lugar onde viviam, possuíam identidade ilhéu e observavam o turismo como benéfico para os moradores locais; porém, sentiam os impactos em seu cotidiano e no ambiente natural que os cercavam. Já a professora, entendia que a atividade turística não influenciava as crianças e não alterava seus cotidianos.

Palavras Chave: Turismo; Crianças; Ilheidade; Infância; Ilha do Mel (PR);

Resumem: Este estudio buscó la mirada de los niños isleños sobre las prácticas turísticas en la región donde viven, contribuyendo a la reflexión sobre la humanización del turismo, conociendo la vida cotidiana, la cultura y los sentimientos de la cultura isleña desde la perspectiva de los niños Los residentes, sin mancha en relación con el turismo en su lugarterritorio. El enfoque utilizado fue etnográfico, basado en observaciones sobre el terreno de cuestionarios y entrevistas aplicadas a los estudiantes del quinto año de una escuela pública de la aldea de Encantadas, en Ilha do Mel y entrevista con el profesor responsable de la clase antes mencionada. Los resultados mostraron que los niños encuestados tenían conocimientos sensibles sobre el lugar donde vivían, tenían una identidad isleña y observaban que el turismo era beneficioso para los residentes locales; Sin embargo, sintieron los impactos en su vida cotidiana y en el entorno natural que los rodeaba. Ya el maestro, entendió que la actividad turística no influyó en los niños y no alteró su vida cotidiana.

Palabras clave: Turismo; Niños; Ilheidade; Infancia; Ilha do Mel (PR).

\footnotetext{
${ }^{1}$ Graduada em Gestão de Turismo pela Universidade Federal do Paraná (UFPR) Setor Litoral, participou como bolsista pela Fundação Araucária do projeto de Iniciação Científica Turismo e Infância: um olhar para as crianças ilhéus paranaenses. Aprovada pela Agência Nacional de Aviação Civil (ANAC) como comissária de voo, atualmente é auxiliar administrativo na empresa BWT Operadora. E-mail - leticiagomesufpr@outlook.com Orcid: https://orcid.org/0000-0001-9709-1647.

2 Bacharelado em Turismo com ênfase em Planejamento Turístico (UFPR), Especialização em Turismo e Meio Ambiente (UNESPAR), Mestrado em Cultura \& Turismo (UESC) e Doutorado em Geografia (UFPR). Atualmente é Professora Adjunta III do Curso de Tecnologia em Gestão do Turismo da UFPR, Setor Litoral e Professora Permanente do Programa de Pós-graduação em Turismo pela UFPR. E-mail - xsayurix@gmail.com Orcid: https://orcid.org/0000-0002-3076-3514
} 
Abstract: The present research the view of islet children on the tourist practices in the region where they live, it sought to reflect and seek the humanization of tourism, knowing the daily life, culture and feelings of happiness from the perspective of children resident and revealing how they relate to tourism in its place-territory. The approach used in the research was the ethnographic, based on observations in loco, interactive questionnaires and interviews, applied to children students of the 5th year of a public school in Vila de Encantadas, Ilha do Mel (PR) and interview with the teacher in charge of the class. The results showed that the children studied had a sensitive knowledge about where they lived, had an island identity, and observed tourism as beneficial to the residents; but they felt the impacts of this practice on their daily lives and the natural environment that surrounded them. Already the teacher, understood that the tourist activities did not influence the children and, therefore, did not alter their daily life.

Keywords: Tourism; Children; Ilheity; Childhood; Ilha do Mel (PR).

\section{Introdução}

O turismo, além de ser um fenômeno marcado pelos deslocamentos, movimenta também as práticas cotidianas, não somente dos turistas, como também de quem permanece em seu habitat natural, especialmente parte da população residente que está ligada diretamente à atividade turística.

O cotidiano dos residentes de regiões turísticas, principalmente em áreas sazonais, se torna facilmente propósito de interferência das práticas realizadas, sendo que as crianças, além dos adultos, podem ser mais um ponto dessas alterações.

Assim, o presente estudo buscou compreender como um grupo de crianças ilhéus percebia o turismo e as possíveis alterações em seu cotidiano. A pesquisa ocorreu na Vila de Encantadas, na llha do Mel, pertencente ao município de Paranaguá no Estado do Paraná, sendo o acesso feito apenas por via marítima.

A llha do Mel, área de estudo do presente trabalho, é um dos maiores atrativos turísticos do Estado do Paraná, entretanto, poucos turistas sabem que a Ilha em sua maior parte é uma reserva ecológica. Segundo o Guia Turístico do site da Prefeitura Municipal de Paranaguá (2017) dos seus 2.700 há, apenas 200 têm permissão de uso, o restante é reserva ecológica (tombada pelo Patrimônio Histórico em 1975 e administrada pelo Instituto Ambiental do Paraná desde 1982).

$\mathrm{Na}$ llha do Mel a implantação de geradores de energia elétrica, em 1988, deu início a atitudes que hoje se transformaram em preocupação pela preservação da ilha e sua principal atração: a natureza (Prefeitura Municipal de Paranaguá, 2017). Por esse motivo e pelas diversas preocupações que surgem acerca da preservação, à exploração do turismo enquanto atividade econômica não deve abster-se de critérios e normas que norteiem seu desenvolvimento e que considere a integração dos aspectos econômicos aos demais aspectos envolvidos (Santos; Pinto \& Santos, 2014). 
Ademais, sobre a questão dos deslocamentos, os únicos modos de locomoção permitidos são o transporte através de bicicleta ou a pé por trilhas ou beira mar. Isso acontece devido à fragilidade ecológica do lugar, sendo $95 \%$ de sua área composta por ecossistemas de restinga e Floresta Atlântica, o que a elevou à categoria de Estação Ecológica em 1982 (Prefeitura Municipal de Paranaguá, 2017).

Além de todos os problemas ambientais, a llha do Mel, como tantas outras, também sofre com a sazonalidade, tendo em alguns períodos do ano, um número muito grande de visitantes, e em outros, quase nenhum. Segundo Carvalho, Decol, Gil e Lanzer (2016), a maior visitação ocorre nos períodos de verão e Réveillon e a permanência em ilhas é em torno de até uma semana.

A partir da busca pelo entendimento dos impactos da turistificação da llha do Mel na vida das crianças residentes, foi elaborado um plano de trabalho desenvolvido em primeiro momento através de pesquisa bibliográfica, e em um segundo momento a pesquisa ocorreu em campo, utilizando como instrumentos de coletas de dados, os questionários, as entrevistas e a observação in loco.

Como objetivos específicos, destacam-se: conhecer o cotidiano e a cultura dos ilhéus a partir da perspectiva de crianças residentes e desvelar como elas se relacionam com o turismo em seu lugar-território; valorizar o patrimônio natural, a cultura local e o cotidiano dos ilhéus a partir da perspectiva de crianças residentes na Ilha do Mel; analisar como o grupo pesquisado de crianças residentes na llha do Mel se relaciona com o turismo.

\section{Revisão de literatura}

As ilhas turísticas gradualmente estão se destacando como destinos muito procurados no Brasil, e, dentre elas, pode-se destacar: a llha do Mel, em Paranaguá, no Estado do Paraná; a llha de Fernando de Noronha, em Pernambuco; a Ilhabela, em São Paulo; Ilha Grande, no Rio de Janeiro; e a Ilha do Marajó, no Pará.

Segundo Cunha e Jacinto (2019) os espaços insulares sempre exaltaram o imaginário e exerceram o fascínio a quem os observa do exterior, alimentado por todo o tipo de literatura de viagens, escritos ao longo dos tempos, por sucessivas gerações de intelectuais de várias proveniências. Com atrativos naturais únicos, as ilhas são consideradas destinos exóticos para o turismo. Assim, a prática turística em ilhas requer a adoção de comportamentos adequados, por parte dos agentes públicos, privados e visitantes, respeitando os limites e favorecendo a preservação dos seus ecossistemas que são tão cobiçados por este público (Carvalho et al., 2016). 
A exoticidade das ilhas tem chamado a atenção de diversos turistas curiosos. Conforme Diegues (1998) "[...] no mundo moderno, as ilhas invadiram os meios de comunicação sendo vistas como últimos redutos do mundo selvagem, lugares paradisíacos para novas descobertas, aventuras e lazer tranquilo, configurando-se como um dos símbolos mais claros do exotismo" (p. 1).

Para o referido autor (1998, grifos nosso) há três conceitos de extrema importância sobre as ilhas. São eles: a maritimidade, que é entendida como um conjunto de várias práticas (econômicas, sociais e, sobretudo simbólicas) resultante da interação humana com um espaço particular e diferenciado do continental. O espaço marítimo, que não é um conceito referente diretamente ao mundo oceânico como entidade física, e sim uma produção social e simbólica que nem sempre existe em todas as sociedades insulares; a insularidade, que é resultante de práticas econômicas e sociais decorrentes da vida num território geograficamente limitado, com fronteiras geográficas e culturais definidas e cercado pelo oceano. Há necessidade de distinguir insularidade e isolamento, pois as ilhas, ainda que parcialmente isoladas, não se desenvolvem em sistemas fechados; vivem, ao contrário, em ritmos alternados de abertura e fechamento, segundo as formas pelas quais estão ligadas à sociedade continental ampla; e a ilheidade, que é o neologismo utilizado pelos pesquisadores franceses (îleité) para designar as representações simbólicas e imagens decorrentes da insularidade, que se expressam por mitos e lendas fundadores das sociedades insulares. Também diz respeito ao vivido pelos ilhéus, aos comportamentos induzidos pela natureza do espaço insular.

Além disso, para Diegues (1998):

Pode-se dizer que o mar é também o elemento fundador da insularidade e da ilheidade. No entanto, sua influência sobre os ilhéus não se dá apenas de forma direta, mas por meio das práticas sociais e simbólicas. Nesse sentido, o mar é visto por algumas sociedades insulares como obstáculo ao contacto com o exterior e por outras como meio de comunicação (p. 88).

Ao se buscar relacionar as questões de ilheidade e insularidade através da perspectiva de crianças, há que se ter uma compreensão da polissemia da palavra infância.

A infância deve ser compreendida e interpretada como uma construção social marcada por variedades; assim, é possível falar em infâncias e não apenas numa infância (Sarmento, 2013). As crianças devem ser percebidas como ativas na construção da sociedade e enquanto sujeitos de relações sociais, merecedoras de estudos a partir de si mesmas (Kramer, 1996).

Desta forma, "tanto o contexto cultural quanto o ambiente físico nos quais se insere a criança caiçara abrangem características peculiares, que demandam a compreensão dos seus aspectos, [...] sobre a maneira como estas crianças constroem seus conhecimentos" (Pereira, 2011, p. 65). 
Segundo o Art. 2ํ da Lei № 8.069, de 13 de julho de 1990 do Estatuto da Criança e do Adolescente "considera-se criança, para os efeitos desta Lei, a pessoa com até doze anos de idade incompletos". Desta forma, entende-se que a criança até que alcance esta idade já se faz presente na sociedade, e os seus entendimentos infantis sobre o mundo já podem ser notados.

Conforme Lopes (2008) há que se romper com as visões reducionistas e adultocêntricas que marcaram nosso olhar sobre as crianças e suas interações com o mundo, outro olhar sobre elas faz-se necessário na constituição de novas políticas educativas na dimensão humana. Assim, nota-se que a interação e a valoração dos saberes infantis não devem fazer-se nulos, ao contrário, devem estar presentes nas relações sociais e culturais que nutrem os conhecimentos infantis e proporcionam esta interação com os mesmos, como complementa Pereira (2011, p. 125):

São os conhecimentos transmitidos durante o cotidiano das comunidades, por meio das relações sociais estabelecidas entre adultos e crianças, assim como entre as próprias crianças, que garantem a inserção do indivíduo no grupo social, proporcionando também a aquisição dos saberes necessários para a sobrevivência no local.

Nesse sentido, entende-se que a inserção da criança na comunidade também se dá através das relações sociais, onde ela adquire experiências e garante-se como ser social. Para tanto, é necessário deixar livres seus entendimentos e cultivos de culturas infantis sem influenciá-las.

Em suas anotações de campo, Lopes e Vasconcellos (2006) afirmam que é importante não falar da existência de uma única cultura própria das crianças, mas sim de culturas infantis, caracterizando desse modo a pluralidade que lhes é inerente. Além disto, tal processo faz emergir junto à ideia de culturas infantis a existência de territorialidades infantis que são base da produção dessa cultura.

Ainda, para os referidos autores (2006) a infância seria a o lugar que cada grupo social destina para suas crianças. O lugar concebido em todas as suas dimensões e simbologia que o envolve. Nesse sentido, as interações que se estabelecem entre sujeitos e lugares não são uma mera relação física, mas uma relação carregada de sentido e mediada pelos sujeitos que o ocupam. Essas interações que marcam a infância fazem com que ela adquira a cultura e o saber do lugar, e através das relações ela estabelecerá quem ela é baseada na simbologia do lugar e das pessoas que a cercam.

Para a aquisição dos saberes dos lugares, Pereira (2011) entende que a adoção da oralidade como meio de difusão de conhecimentos tradicionais torna possível a afirmação de que as comunidades caiçaras apresentam a educação informal como principal mecanismo de transmissão dos valores, signos e saberes específicos sobre o meio local. Bem como Diegues (1998) que descreve a identidade insular como uma construção através 
de diversos elementos, de seu lugar de origem e das pessoas que a detém. Nas palavras do autor, "o mar em torno da ilha e a terra vista da imensidão marítima, tal é a configuração física que constitui os elementos materiais e cognitivos da identidade insular" (Diegues, 1998, p. 116).

\title{
Metodologia
}

Por meio de uma abordagem etnográfica, buscou-se uma maior compreensão de informações e a qualidade das mesmas para a análise da percepção de crianças ilhéus quanto ao turismo no ambiente em que elas vivem. Nesse sentido, deve-se compreender quais são os objetivos do pesquisador etnográfico:

[...] a etnografia é uma forma especial de operar em que o pesquisador entra em contato com o universo dos pesquisados e compartilha seu horizonte, não para permanecer lá ou mesmo para atestar a lógica de sua visão de mundo, mas para, seguindo-os até onde seja possível, numa verdadeira relação de troca, comparar suas próprias teorias com as deles e assim tentar sair com um modelo novo de entendimento ou, ao menos, com uma pista nova, não prevista anteriormente (Magnani, 2009, p. 135).

Há três características da descrição etnográfica: ela é interpretativa; o que ela interpreta é o fluxo do discurso social e a interpretação envolvida consiste em tentar salvar o "dito" num tal discurso da sua possibilidade de extinguir-se e fixá-lo em formas pesquisáveis. (Geertz, 1989).

A partir das características da descrição etnográfica, parte-se para a compreensão dos momentos em se deve utilizá-la.

\begin{abstract}
Sintetizando ideias de vários outros autores, podemos dizer que o estudo de caso etnográfico deve ser usado: (1) quando se está interessado numa instância em particular, isto é, numa determinada instituição, numa pessoa ou num específico programa ou currículo; (2) quando se deseja conhecer profundamente essa instância particular em sua complexidade e em sua totalidade; (3) quando se estiver mais interessado naquilo que está ocorrendo e não como está ocorrendo do que nos seus resultados; (4) quando se busca descobrir novas hipóteses teóricas, novas relações, novos conceitos sobre um determinado fenômeno; e (5) quando se quer retratar o dinamismo de uma situação numa forma muito próxima do seu acontecer natural (André, 2005, p. 44).
\end{abstract}

A partir da compreensão de quando utilizar a etnografia, sugerida pelo referido autor, entende-se que este é um método complexo e que exige profunda dedicação de seus pesquisadores para que se possa estudá-lo e utilizá-lo de maneira correta, procurando sempre apreciar as suas atividades e entende-las de modo que haja concisão nos passos a serem seguidos.

"As operações de ver e descrever, longe de simultâneas, encontram-se separadas por um intervalo de tempo, [...] é preciso suspender uma das atividades de modo que a 
outra possa se realizar" (Peixoto, 2011, p. 203). Isto é o que a etnografia busca e o que os pesquisadores devem buscar a pausa para o entendimento de cada fase que configura a pesquisa é a parte mais importante para a real compreensão do que se procura, a observação e a descrição são partes fundamentais, e só haverá a compreensão do todo se cada fase for devidamente trabalhada e entendida pelo pesquisador.

Desta forma, além dos estudos referenciais apontados aqui para poder aproximar-se da etnografia, foram realizadas visitas a campo para observar o cotidiano das crianças dentro da escola e pesquisar o que elas compreendem sobre o turismo colocando em prática tudo o que foi observado sobre a etnografia no contexto de pesquisa.

Para André (2005) conhecer a escola mais de perto significa colocar uma lente de aumento na dinâmica das relações e interações que constituem o seu cotidiano, e só a partir do convívio com o lugar-território das crianças é que se pode estudá-las, pois sem o conhecimento do lugar não há como entender as configurações sociais e culturais a que a ela pertence.

Anterior à aplicação da pesquisa etnográfica, utilizou-se os seguintes documentos: o aceite das crianças em relação ao projeto, onde cada uma delas aceitava ou não participar, assegurando-Ihes preservar a sua identidade por meio de um nome fictício para ser utilizado durante a pesquisa; um questionário interativo que continha 10 questões, sendo que 9 destas eram questões dissertativas e 1 era para responder a partir de desenhos, e todas elas foram compostas a partir das principais considerações que foram relacionadas ao tema a que se busca entender através dos autores aqui já referenciados (essas questões tratam da ilheidade como característica cultural e social; do turismo e da sazonalidade e como isso afeta o cotidiano das crianças e os espaços infantis; e da relação com a insularidade e maritimidade a que se tem com o ambiente natural da ilha); e seguindo a proposta da busca pelo conhecimento denso desenvolveu-se uma entrevista semiestruturada com cerca de 8 perguntas, com os mesmos temas do questionário, a serem desenvolvidas ao longo de uma conversa com os alunos.

Anterior às visitas de campo, realizou-se uma oficina sobre pesquisa com crianças, o que orientou sobre como manusear e aplicar os instrumentos de coleta de dados com crianças e como se portar diante delas para que não houvesse nenhum tipo de estranhamento ou rejeição das mesmas, respeitando-as enquanto cidadãs em formação. 


\section{Resultados e discussão}

No dia 17 de abril de 2017 foi realizada a primeira visita de campo, na escola Rural Municipal Teodoro Valentim com o objetivo de fazer o primeiro contato com os integrantes da pesquisa e observar a rotina das crianças dentro do ambiente escolar.

A escola se situa no mesmo prédio que a escola estadual, por conta do pequeno número de estudantes. O lugar contava com ambientes que são compartilhados, como a área aberta para atividades ao ar livre na entrada da escola e o refeitório que fica de frente para esta área. A escola também possuía três salas, sendo uma para depósito de materiais e duas para ministrar aulas.

A partir da determinação da idade da turma que participaria da pesquisa, o 5. (quinto) ano letivo do ensino fundamental foi escolhido, para que se pudesse com crianças e que essas pudessem ter o entendimento mais conciso sobre os referidos temas a serem abordados. Os 4 alunos que compunham o 5. (quinto) ano tinham aulas ministradas juntamente com o 4. (quarto) ano, por conta da pouca quantidade de alunos, ambas turmas regidas por uma mesma professora.

No primeiro dia de visita foi realizado contato com os funcionários da escola sendo eles receptivos à pesquisa. A coordenadora da escola não se encontrava naquela data, e assim contatou-se a Secretaria Municipal da Educação de Paranaguá para que a pesquisa fosse autorizada e os termos de consentimento (TCLE) a serem assinados pelos pais entregues no mesmo dia à professora da turma para aguardara autorização e dar continuidade à pesquisa.

No dia 26 de abril de 2017 foi realizada a segunda visita de campo com o intuito de aplicar os instrumentos de coleta de dados e investigar quais as concepções das crianças em relação ao turismo, a cultura ilhéu e o meio ambiente em que vivem. Chegando à escola notou-se que era um dia atípico para os estudantes, pois havia acabado a luz e sem ela não haveria como seguir com as atividades letivas previstas. Assim, enquanto outras atividades eram realizadas (com o consentimento da professora responsável) os três alunos do 5. (quinto) ano, sendo que um deles não estava presente, foram encaminhados a uma sala onde foram explicados os propósitos da pesquisa e após a assinatura do aceite das próprias crianças, o questionário interativo foi aplicado. Em seguida, conforme o término dos questionários, as crianças auto interpretaram os seus desenhos (referente a uma pergunta do questionário que solicitava que respondessem em forma de desenho).

No dia 24 de maio de 2017 foi realizada a terceira e última visita a escola para que a pesquisa de campo fosse concluída e que todos os alunos estivessem inseridos. Nesta data, os alunos estavam reunidos na sala dos professores, pois uma atividade diferenciada sobre o folclore estava sendo ministrada aos alunos do $3 . .^{\circ}, 4 .^{\circ}$ e $5 .^{\circ}$ ano. Assim, com a autorização 
da coordenadora da escola, a aluna que não esteve presente na terceira visita aceitou participar da pesquisa, respondendo ao questionário e sendo entrevistada.

No transcorrer do campo, notou-se que os alunos já questionados mantinham-se interessados, pois todos relataram que estavam felizes pela continuação da pesquisa além de contar algum fato novo ou história que não haviam se lembrado da última vez.

Há que se ressalvar que todos os processos anteriores à aplicação da pesquisa junto aos estudantes pesquisados foram realizados como previsto, com a cooperação dos alunos, de seus responsáveis e da escola.

Os 4 alunos pesquisados (que serão representados aqui pelos nomes fictícios escolhidos por eles de Zeus, Joaquim, Exi e Karol) que tinham idade entre 10 e 12 anos, sendo Joaquim e Zeus moradores a mais de 10 anos da llha do Mel; Karol a 3 anos e Exi a apenas 2 semanas.

Em relação à classe social perguntou-se quais os empregos dos pais e responsáveis, sendo um marceneiro, um açougueiro e um dono de pousada.

Indagados sobre se considerar caiçara e porque, dois dos alunos (Zeus e Joaquim) disseram que se consideravam caiçaras porque moravam na ilha, enquanto Karol se considerava caiçara por ter nascido em Paranaguá, e, um dos alunos mencionou não se identificar como caiçara (Exi). Percebe-se que 3 das crianças demonstram identidade insular, apresentando sentimentos de pertencimento ao lugar quando disseram que são caiçaras reforçando a ideia ao justificar que isso se dá por morarem na llha do Mel. A única criança que não se considera caiçara é justamente aquela que morava na ilha a duas semanas.

No questionamento sobre as particularidades do lugar em que vivem, Zeus e Exi identificaram o acesso a ilha (de barco), sendo ainda, a fauna e a flora um diferencial. Karol identificou falta de moto e de carros. Essa percepção infantil caracteriza a relação com o meio ambiente, com a maritimidade e a insularidade descrita por Diegues (1998), pois identifica o acesso a ilha como algo bom, que traz pessoas e não como algo que as distancia do continente.

Sobre a valorização e interesse tanto dos turistas quanto dos moradores em relação ao meio ambiente, Joaquim acredita que moradores cuidam do meio ambiente na ilha e os turistas não. Zeus e Karol disseram que só alguns cuidam do meio ambiente e Exi respondeu que moradores e turistas cuidam da ilha "porque é um meio de preservação ambiental". Nota-se o conhecimento ambiental que as crianças possuem, e, além disto, a cultura da comunidade local e dos turistas visitantes é comparada, mostrando que as crianças vivenciam situações distintas em seus cotidianos. 
Questionados sobre a existência de diferenças no cotidiano entre a alta e a baixa temporada as crianças responderam que há mudanças, sendo elas na quantidade de pessoas ocupando a ilha e nas vestimentas dos visitantes. Desta forma, pode-se notar que o turismo e sazonalidade na região refletem mudanças no cotidiano das crianças e afetam os espaços infantis. Eles também citaram diferenças culturais do modo de vida urbano, como quando veem turistas vestidos com calças no verão e estranham, pois não estão habituados a essas roupas no calor.

Perguntados se já haviam conhecido alguma pessoa que mora ou já morou em outra ilha, o desconhecimento de moradores de outras ilhas foi retratado por três alunos, sendo Joaquim o único que já conheceu, mostrando que as características socioculturais são particulares de cada região ilhéu, não havendo muito contato entre as crianças que as habitam.

Na pergunta sobre o prejuízo ou benefício do turismo para o local em que vivem Zeus respondeu que o turismo "ajuda os moradores a ganhar dinheiro" demonstrando a influência dos pensamentos adultocêntricos na infância, como já salientado em citações tais como a de Lopes (2008), e Joaquim mostrou-se incomodado quando mencionou que "prejudica por fazerem muitos barulhos à noite".

Em relação à diferença de cultura entre moradores e turistas, um dos alunos (Exi) mencionou existirem hábitos diferenciados e Karol respondeu: "sim, porque as roupas e o jeito de falar, o estilo [sic] são diferentes". Assim, pode-se perceber, a partir da resposta das referidas crianças, que elas identificam o que não Ihes é familiar como diferença cultural entre eles.

Sobre seus lugares favoritos na ilha, Zeus disse que "são todos porque adoro ela"; Joaquim citou "Fortaleza, Farol Miguel, Bela Galheta, Praia Grande e Gruta" e Karol destacou também sua casa (que segundo ela é onde passa a maior parte do tempo): " $A$ praia, o trapiche e a minha casa". A relação com a insularidade, ilheidade e o meio ambiente na ilha está presente no discurso das crianças, mostrando que elas têm a ilha como seu espaço.

Em outra pergunta, questionados se recomendariam a llha do Mel como destino de visitação àqueles que não a conhecem, todas as crianças responderam que sim.

Sobre responder o que é turismo através de um desenho, três alunos representaram barcos, como meio de chegada a ilha ou de visitação entre ambientes desta, caracterizando a natureza, o mar, e animais nativos viventes ali, além de pessoas felizes indo passear na ilha e admirando as paisagens.

O desenho do Joaquim, em sua própria interpretação representa "um passeio de barco da Fortaleza até o Belo (Brasília), tem muito peixe e pássaro e pessoas tirando foto". 
Figura I: O Que é Turismo para Joaquim.

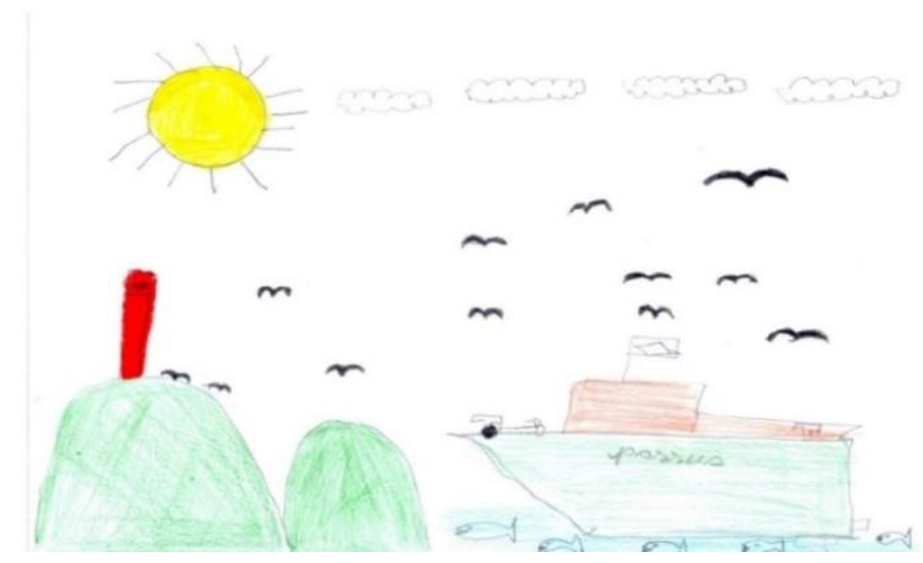

Fonte: Pesquisa de Campo (2017).

O desenho do Zeus representa um "barco de Paranaguá a Encantadas levando turistas no feriado. O morro é à frente da Encantada e o peixe é porque tem bastante aqui!".

Figura II: O Que é Turismo para Zeus.

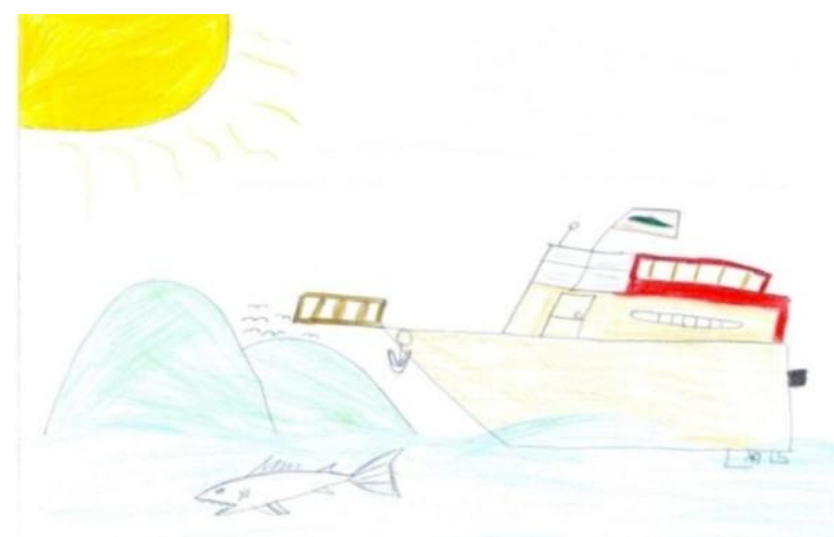

Fonte: Pesquisa de Campo (2017).

O desenho do Exi "É um barco indo pra llha. Todos os turistas estão passeando, as malas estão ali em cima do barco e tem golfinhos na água."

Figura III: O Que é Turismo para Exi. 


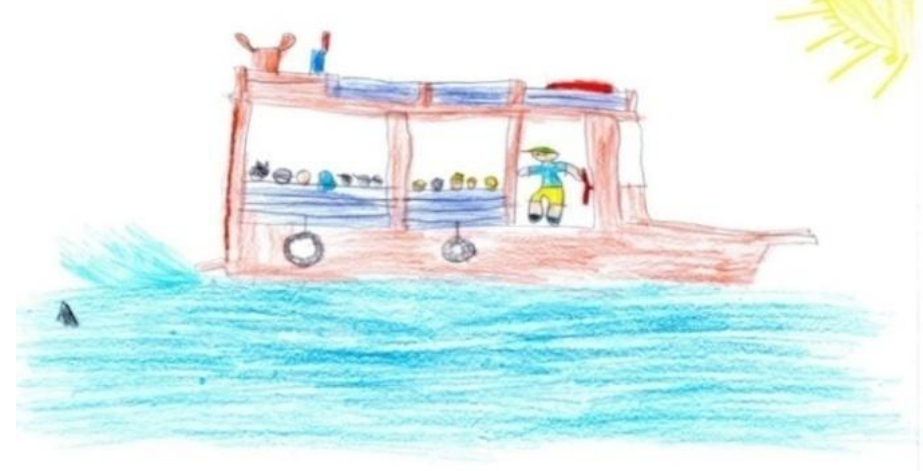

Fonte: Pesquisa de Campo (2017).

Karol desenhou várias pessoas andando entre as casas e fotografando o mar e a paisagem. Segundo ela seus pais trabalham mais na temporada e ela passa mais tempo em casa.

Figura IV: O Que é Turimo para Karol.

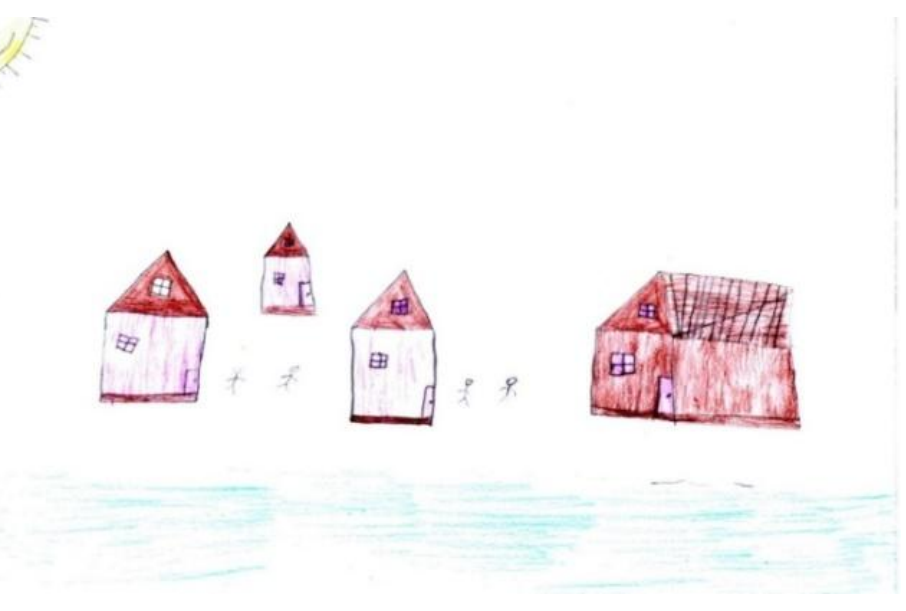

Fonte: Pesquisa de Campo (2017).

Dessa forma evidenciam-se as diferenças entre as próprias crianças ilhéus, onde três delas se mostram entusiasmadas com a chegada da temporada de verão onde o turismo é mais praticado na ilha, e a outra criança mostra que o turismo tem influência e causa impactos na sua infância, pois os pais trabalham mais e lhes dão menos atenção e liberdade. Assim, nota-se que o turismo também causa impacto na vida das crianças.

Após a aplicação do questionário, as crianças foram entrevistadas. Durante as entrevistas, buscou-se ter empatia para com elas, valorizando o tom de conversa e respeitando-as enquanto cidadãs em formação.

Suscitadas a se expressarem mais sobre se a llha do Mel é um bom lugar para morar, os alunos citaram principalmente a tranquilidade em relação à correria de carros e os 
perigos das grandes cidades, sendo a ilha um lugar que dá para brincar, andar e aproveitar o mar sem riscos de atropelamento. Karol disse que "Sim, gosto da praia e do mar de fora"; além disto, nenhuma delas gostaria de morar em outro lugar. Percebe-se que desde o começo da entrevista as crianças demonstram ter vínculo afetivo com a ilha, pois cada comentário sobre os ambientes urbanos trazia a impressão de não ser algo bom, justamente ao contrário do ambiente ilhéu.

Após a solicitação da descrição da ilha em uma palavra ou frase, surgiram em resposta, às palavras "legal, bom, bonito e feliz". Como na primeira questão, as crianças continuaram a evidenciar as qualidades da ilha.

Em relação à natureza, os alunos demonstram conhecimento e interação, descrevendo na maioria de suas atividades práticas no meio ambiente como trilhas, stand up, pesca, subir em árvores, jogar bola (futebol), entrar no mar, brincar, andar de bicicleta. Joaquim citou como uma de suas práticas limpar os lixos jogados do chão. Indagado sobre a prática de limpeza, Joaquim respondeu que tem muito lixo na localidade e que não são apenas os turistas que jogam lixo, mesmo sendo os principais agentes poluidores, os moradores também jogam lixo no chão.

Percebeu-se que a pesca pode ser entendida como uma das principais ligações com a maritimidade, além de representar a cultura caiçara caracterizando ainda a ilheidade; já a prática de limpar os lixos como foi descrito por Joaquim torna perceptível um dos principais impactos da turistificação na ilha, a poluição que ela traz, mas que também cabe aos próprios moradores.

Perguntados sobre a existência de museus na ilha, Karol respondeu que não havia; porém, duas crianças citaram o Forte e Zeus falou sobre as paradas turísticas. Três deles sabiam histórias sobre a ilha, como a da sereia contada em versões parecidas por Zeus e Karol: "A da sereia, que morava uma sereia na gruta e ela cantava pros [sic] pescadores pra afogar eles no mar" contou Karol. Eles mencionaram que familiares contaram as histórias e que provavelmente é assim que as transmitem "Eu acho que foi a minha bisavó que contou pra [sic] minha vó que contou pra [sic] mim que daí quando eu tiver um filho que se tiver um neto daí eu vou contar também" disse Zeus.

Observou-se que as crianças detinham conhecimentos históricos tradicionais da llha do Mel, além de caracterizarem a ilheidade como forte instrumento simbólico de transmissão da cultura oral e da tradição ilhéu através de contos e histórias que são passados hereditariamente.

Sobre o interesse dos turistas pelas histórias da llha, foi percebido pelas crianças como pouco, pois para elas, os turistas não vão para a ilha em busca de cultura e conhecimento, apenas para desfrutar as belezas naturais. Porém, o conhecimento das 
histórias da ilha pelos turistas é visto como necessário, pois despertaria o interesse dos visitantes pelo lugar, como mencionou Karol "Acho que sim, porque o lugar tem bastante histórias, tem bastante lugares pra [sic] passear". A maioria das crianças concorda que os turistas teriam maior interesse se soubessem das histórias e da cultura do lugar que visitam.

A respeito do que as crianças gostariam que tivesse na ilha ou que fosse melhorado, Exi citou a liberação de obras, dizendo que seu pai comentou que elas são embargadas pelo IAP (Instituto Ambiental do Paraná); Joaquim espera que o campo de futebol seja arrumado; e Karol não melhoraria nada. Todos eles acham que o IAP e/ ou a Prefeitura deveriam resolver esses problemas.

Questionados se na escola alguém já havia dialogado com eles sobre o turismo, Zeus mencionou que um dos professores já abordou o tema como um benefício para a ilha por conta de os turistas trazerem dinheiro e gastarem com meios de hospedagem, alimentação e outros; e Joaquim falou que o mesmo professor o ensinou que deve-se ajudar os turistas indicando onde ficam os lugares. Os 4 gostariam de aprender mais sobre turismo.

Além das atividades propostas para as crianças também foi realizada uma entrevista com a professora da turma que atuava na escola há 7 anos, tendo se mudado de Paranaguá para a llha do Mel exclusivamente para dar aulas após ser aprovada em concurso público.

Segundo a professora, os temas turismo, identidade cultural ilhéu e preservação do meio ambiente já foram abordados durante as aulas, sendo realizadas atividades dentro e fora de sala.

Em relação a passeios e saídas de campo com propósito de aprendizagem, a professora explicou que os alunos já saíram para conhecer o fórum, o porto e o museu (na cidade de Paranaguá) dentro de projetos realizados e mencionou que os alunos costumam sair da ilha com os pais. Além disso, para a professora as tradições regionais como as histórias populares fazem parte da cultura e do aprendizado das crianças, e por este motivo, segundo ela, até mesmo através do artesanato as crianças saem da sala para recolher conchas na praia e fazer esses e outros trabalhos que interliguem o meio ambiente, a identidade ilhéu e as tradições regionais de conservação:

Eu gosto de sair com as crianças, eu gosto de contar sobre a ilha, de ver o que a ilha tem, de mostrar pra eles e trabalhar juntos. E eles também trazem bastante coisa pra [sic] gente, porque conversando com eles já vem de casa com aquilo que os pais falam né, e eles passam pra gente. A gente conta na escola e eles interagem com as histórias, cada um fala um pouco. De llha a gente sabe tudo! (Professora da turma, informação oral). 
Em continuidade, a referida professora mencionou que por possuir muitas famílias tradicionais na ilha, muitas das crianças possuem a essência do ser caiçara e mantém algumas tradições ilhéus.

Questionada sobre notar alguma diferença de comportamento das crianças próximo a feriados prolongados ou férias na alta temporada quando a ilha recebe uma grande demanda de turistas, a professora respondeu que o cotidiano e o comportamento das crianças não costumam se alterar. Para ela, por crescerem na ilha e viverem as alterações por conta da sazonalidade se tornou algo comum para as crianças. Sendo assim, para a professora, a infância dessas crianças residentes da ilha não é prejudicada pelo turismo por ser algo típico da região: "Eu acho que para eles já é normal. Desde sempre, porque sempre tem gente aqui, então pra eles é normal".

A partir da entrevista entendeu-se que para a professora as crianças são acostumadas com as atividades turísticas e por isto não sentem os impactos da mesma durante o seu cotidiano. Para ela a sazonalidade é característica do local e assim os moradores não percebem problemas.

\section{Conclusões}

Por meio da revisão de literatura e dos questionários e entrevistas aplicadas às crianças e a educadora ao longo da pesquisa, pode-se alcançar os objetivos propostos além de ter vivenciado o cotidiano e a cultura dos ilhéus a partir da perspectiva de crianças residentes, conseguindo desvelar como elas se relacionavam com o turismo em seu lugarterritório oportunizando a valorização do patrimônio natural, da cultura local e do cotidiano dos ilhéus a partir da perspectiva de crianças residentes na llha do Mel, concluindo a investigação de como as crianças se relacionavam com o turismo.

Por meio de análise das informações obtidas, compreendeu-se que as crianças tinham sensível conhecimento sobre o lugar que viviam, mostrando dos saberes mais complexos como o nome de órgão de competência ambiental, até os mais tradicionais como as histórias que são repassadas de pais para filhos na ilha.

A identidade ilhéu foi percebida como forte característica no perfil desses residentes, pois o sentimento de pertencimento ao seu lugar-território se fazia presente em quase todas as falas das crianças, mostrando que gostavam de onde viviam, que recomendariam a qualquer pessoa que o visitasse, e ainda que não gostariam de se mudar dali.

Do mesmo modo em que enaltecem a llha do Mel, os entrevistados demonstravam que também sabiam dos problemas enfrentados em decorrência da atividade turística e entendem que alguns turistas não cuidam e não se interessam pela história da ilha e de 
seus moradores chegando a incomodar por conta de ruídos excessivos e pelo lixo que é usado como exemplo por um deles como algo ruim, sentindo a partir desse e de outros problemas os impactos desta prática em seu cotidiano infantil e no ambiente natural que os cerca, mas, ainda assim, optavam por privilegiar os benefícios derivados dele acreditando que o turismo é benéfico para a ilha e para seus moradores, tanto pela questão financeira (indicada como benefício aos pais e até por professores), quanto pelas relações sociais, representadas por elas nas amizades formadas na alta temporada com as crianças turistas.

Também pode-se notar as diferenças entre o cotidiano de uma das alunas que passava a maior parte do tempo em casa por conta do trabalho dos pais na temporada enquanto os seus colegas de classe desfrutam das férias e das novas amizades. Esta situação retrata que o cotidiano de todas as crianças pesquisadas se altera durante a temporada de verão e feriados prolongados, assim, mesmo que de maneiras diferentes na vida de cada um o fluxo turístico na llha do Mel influência na rotina de tais crianças.

Além disso, pode-se perceber que a professora entendia que as atividades turísticas não influenciavam as crianças por serem atividades corriqueiras na ilha e por este motivo elas já estariam acostumadas às decorrências da mesma e, portanto, não alteravam o cotidiano infantil. A educadora indicou também que a escola se empenhava em fomentar a adição de saberes culturais e tradicionais ilhéus na vida das crianças, além dos já préestabelecidos pelo ensino infantil do país, levando-as para visitas e estudos além da sala de aula.

Assim, a partir dos resultados obtidos, este trabalho poderá contribuir para futuros projetos e pesquisas (utilizando-a como referência bibliográfica para apoiar os estudos), tanto na Ilha do Mel como em outras ilhas turísticas e/ou com potencial turístico para que possam auxiliar a manter a identidade cultural das crianças ilhéus e proporcionar maior interação com o turismo em sua comunidade de forma saudável e sustentável a fim de valorizar o meio ambiente e a cultura mostrando que as crianças também são importantes agentes de mudanças e detentoras de sabedorias específicas.

\section{Referências bibliográficas}

André, M. E. D. A. de. (2011) Etnografia da Prática Escolar. Ed.18, São Paulo: Papirus.

Carvalho, R. G. A., Decol, F., Gil, L. F. \& Lanzer, R. M. (2016) Um estudo sobre as atividades turísticas em seis ilhas brasileiras. Revista Brasileira de Pesquisa em Turismo, São Paulo, v. 10, n. 1, p. 173-188. ANPTUR - Associação Nacional de Pesquisa e Pós-Graduação em Turismo.

Diegues, A. C. (1998) Ilhas e Mares: Simbolismo e imaginário. São Paulo: Hucitec Nupaub.

Brasil. (1990) Estatuto da Criança e do adolescente. Lei № 8.069, De 13 De Julho De 1990. Disponível em: <http://www.planalto.gov.br/ccivil_03/leis/L8069.htm> Acesso em: 11 AGO 2017. 
Cunha, L. \& Jacinto, R. (2019). Turismo e Desenvolvimento dos Territórios Insulares: Apontamentos para uma Geografia do Turismo de Cabo Verde. Imprensa da Universidade de Coimbra. Coimbra.

Geertz, C. (1989) A Interpretação das culturas. Rio de Janeiro, LTC.

Kramer, S. (1996) Pesquisando Infância e educação: um encontro com Walter Benjamin. In: Kramer, S. \& Leite, M. I. (Orgs.) Infância: fios e desafios da pesquisa. Campinas: Papirus, p. 14-38.

Lopes, J. J. M. \& Vasconcellos, T. (2006) Geografia da Infância: Territorialidades Infantis. Currículo sem Fronteiras, Rio de Janeiro, n. 1, p. 103-127.

Lopes, J. J. M. (2008) Geografia das Crianças, Geografia das Infâncias: as contribuições da Geografia para os estudos das crianças e suas infâncias. Contexto e Educação, editora Unijuí, n. 79, p. 65-82.

Magnani, J. G. C. (2009) Etnografia como Prática e Experiência. Horizontes Antropológicos, Porto Alegre, n. 32, p. 129-156.

Peixoto, F. A. (2011) O olho do etnógrafo. Sociologia \& Antropologia. Rio de Janeiro, v. 1, p. 195-215.

Pereira, B. E. (2011) Crianças Caiçaras de Guaraqueçaba - PR: Relações com a natureza. Dissertação (Mestrado) - Curso de Ciência Ambiental, Energia e Eletrotécnica, Universidade de São Paulo, São Paulo.

Prefeitura Municipal de Paranaguá - PR. (2017) Guia Turístico - Ilha do Mel. Disponível em: $<$ http://www.paranagua.pr.gov.br/conteudo/guia-turistico/ilha-do-mel> Acesso em: 21 ABR 2017.

Santos, S. R.; Pinto, P. A. \& Santos, P. C. (2014) Ilha do Medo: proposta de uma nova opção de produto turístico para a cidade de São Luís (MA). Revista Brasileira de Ecoturismo, São Paulo, v. 8, n. 7, p. 444-461.

Sarmento, M. J. (2013) A Sociologia da Infância e a sociedade contemporânea: desafios conceituais e praxeológicos. In: ENS, R. T.; GARANHANI, M. C. Sociologia da Infância e a formação de professores. Curitiba: Editora Champ. 